\title{
¿Qué sabemos de los odontólogos extranjeros ejerciendo en Chile?
}

\section{What do we know about foreign dentists practicing in Chile?}

\author{
Moscoso-Matus K..$^{1,2}$, Guzmán D. ${ }^{3}$, Naser F. ${ }^{3}$, San Martín MT. ${ }^{3}$
}

1. Escuela de Odontología, Facultad de Medicina, Pontificia Universidad Católica de Chile, Santiago, Chile.

2. Fundación Sonrisas, Santiago, Chile.

3. Estudiante $6^{\circ}$ año Escuela de Odontología, Facultad de Medicina, Pontificia Universidad Católica de Chile, Santiago, Chile.

*Correspondencia a: Moscoso-Matus, Karla , DDS, MBA | Dirección: Av. Vicuña Mackenna 4860,

Macul, Santiago, Chile. | Email: kmoscoso@uc.cl Trabajo recibido 26/07/2021

Aprobado para su publicación 07/08/2021

\section{Sr Editor.}

Es un sano ejercicio democrático la solicitud de transparencia. Así está reconocido en el artículo $8^{\circ}$ de la Constitución vigente al día de hoy y así mismo es consagrada por la Ley 20.285 promulgada el 2008 sobre acceso a la información pública. Esta herramienta no solo ha permitido develar el funcionamiento del estado al público general y contribuido a las buenas prácticas, sino que también ha sido utilizado con fines investigativos. Como resultado de lo anterior, se ha generado un virtuosismo académico que puede traducirse en mejoras.

El año 2007 con datos obtenidos vía ley de transparencia, junto a la Dra. Iris Espinoza de la Universidad de Chile, publicamos en este mismo medio un artículo(1) ${ }^{(1)}$ sobre la subutilización de las facultades que la Ley 19.937 confiere al Registro Nacional de Prestadores Individuales, específicamente referido a la ausencia del dato de lugar de desempeño. Este hecho o tal vez una simple causalidad, condujo a que al día de hoy ese antecedente ya esté incorporado, y si bien el $43,5 \%$ de los registros aún no posee este antecedente, es una mejora sustantiva.

A través de esta misma fuente de datos, logramos determinar que al 04 de mayo 2021 existen 2591 odontólogos extranjeros. Del total de odontólogos en Chile, el 32,05\% tienen al menos una especialidad. De éstos sólo 674 se consignan como extranjeros.

Según un informe del Instituto Nacional de Estadística (INE) junto con el Departamento de Extranjería y Migración ${ }^{(2)}$ (DEM), el flujo migratorio en nuestro país superó 1,4 millones de personas para 2019 y el INE(3), con datos censales 2017 , estimó que el $77,6 \%$ de los migrantes proviene de: Perú $(25,2 \%)$, Colombia $(14,1 \%)$ y Venezuela $(11,1 \%)$, seguido por Bolivia $(9,9 \%)$, Argentina $(8,9 \%)$ y Haití $(8,4 \%)$. La comunidad ecuatoriana tiene una representación muy menor. Ante ello, pareciera resultar inconsistente que nuestro registro de prestadores consigne que el porcentaje mayoritario de dentistas extranjeros son colombianos o ecuatorianos, representando el $48,1 \%$ y $32,7 \%$ respectivamente. Por el contrario, los dentistas peruanos representan el $1,9 \%$ y los venezolanos el $3,4 \%$. La situación recién descrita pudiese ser explicada porque las olas migratorias asociadas a Colombia y Ecuador están conformadas por personas con mayor calificación académica versus la de otros países latinoamericanos, y/o las asimetrías en la convalidación de los títulos de uno u otro país. Se debe recordar la existencia de a lo menos 3 vías para el reconocimiento del título en Chile, las cuales son convalidación vía Ministerio de Relaciones Exteriores, donde sólo se efectúa una tramitación administrativa y no implica la realización de exámenes de conocimientos ni prácticos (válido para Bolivia, Brasil, Colombia, Costa Rica, El Salvador, Guatemala, Honduras, Nicaragua, Perú y Uruguay), reconocimiento vía Ministerio de Educación (para Argentina, Ecuador, España y Reino Unido) $^{(4)}$ y convalidación ante la Universidad de Chile para todos los demás, donde sí se requiere la realización de exámenes ${ }^{(5)}$.

Las alternativas que explican las diferencias en la representaciones de los odontólogos extranjeros en el registro de prestadores pudiese estar evidenciando un subregistro, principalmente de los provenientes de Perú y Venezuela. Esta situación es particularmente grave, pues implica la existencia de profesionales ejerciendo la profesión sin cumplir los requisitos legales y sanitarios, con los riesgos que ello pudiera conllevar. Por el contrario, una clara identificación de la nacionalidad de los profesionales extranjeros existentes en nuestro país es una oportunidad para las casas de estudio, ya que significa la posibilidad de incorporar talento humano capacitado y al mismo tiempo, una potencial masa crítica que requiere conocer nuestro sistema de salud y mantener al día sus conocimientos. Sin lugar a dudas, esta es una opción muy apetitosa para las Universidades.

La visibilización de los datos de odontólogos extranjeros entregados vía ley de transparencia nos generó como equipo investigador mucha curiosidad, y en el afán de buscar explicaciones, simulamos una solicitud de incorporación al registro de prestadores individuales, vía online. Nuestra sorpresa es que es un sistema de autollenado, donde la plataforma permite el ingreso de sólo una nacionalidad y no consulta sobre lugar de nacimiento, o mejor aún, si se tiene otra nacionalidad. Dado que para completar la casilla como "chileno" se debe haber nacido en Chile u optar a la nacionalización después de 5 años de residencia en el país, nuestra curiosidad se vio aumentada. Por ejemplo, si en el momento del registro se obtuvo la nacionalidad chilena a través de un formulario de autollenado, ante la pregunta de Cuál es su nacionalidad, ¿qué se debe contestar? ¿Qué porcentaje de personas del registro cumple la condición de ser chileno y cursar estudios de odontología en el extranjero? ¿Tiene impacto sanitario el que sea más dificultoso para 
unos países que para otros ejercer en Chile?

Sin lugar a dudas, mejorar el formulario de incorporación al registro de prestadores individuales permitiría tener mejor conocimiento de los profesionales que se desempeñan en nuestro país y con ello, diagnosticar y planificar mejor el recurso humano sanitario.

\section{Bibliografía}

1. Moscoso-Matus K, Espinoza-Santander I. Odontólogos: ¿Cuántos somos y en qué lugar de Chile ejercemos nuestra profesión?. Rev Clin Periodoncia Implantol Rehabil Oral. 2017;10(2):75-6.

2. Instituto Nacional de Estadísticas, Departamento de Extranjería y Migración. Estadísticas migratorias. Estimación de personas extranjeras residentes habituales en Chile al 31 de diciembre de 2019. Informe técnico: desagregación regional y comunal. Junio 2020. [Citado 07/07/2021]. Disponible: https://www.extranjeria.gob.cl/ media/2020/06/estimaci\%C3\%B3n-poblaci\%C3\%B3n-extranjera-en-chile-2019-regiones-y-comunas-metodolog\%C3\%ADa.pdf

3. Instituto Nacional de Estadísticas. Características sociodemográficas de la in- migración internacional en Chile: Censo 2017. Síntesis de Resultados. Noviembre 2018. [Citado 07/07/2021]. Disponible: http://www.censo2017.cl/descargas/ inmigracion/181126-sintesis.pdf

4. Solicitud de registro de títulos obtenidos en el exterior. [Citado 07/07/2021]. Disponible: https://www.minrel.gob.cl/reconocimiento-de-titulos/minrel_old/2010-0526/112420.html

5. Reconocimiento de Títulos y Grados Extranjeros mediante Convenios vigentes con Chile. [Citado 07/07/2021]. Disponible: https://www.uchile.cl/portal/presentacion/relaciones-internacionales/revalidacion-de-titulos-extranjeros/159574/reconocimiento-de-titulos-extranjeros-mediante-convenios. 